\title{
EL DESARROLLO DE LA SOCIEDAD COMPLEJA EN EL VALLE DE CASMA
}

\author{
Shelia Pozorski
}

Thomas Pozorski

\section{Resumen}

$\mathrm{L}$ as ciudades complejas desarrollaron cerca grupos de montículos monumentales en el valle de Casma durante el Período Inicial o Formativo Temprano, alrededor de los 1500 años a. C. Entre ellos, el sitio más conocido hasta el momento es Pampa de las Llamas-Moxeke, pero éste es solamente uno entre varios sitios importantes del mencionado valle durante aquella época y la anterior, el Precerámico Tardío. Este artículo examina los orígenes de algunas características presentes en los sitios del Precerámico Tardío, las cuales se acentuaron en el período Inicial en sitios como Pampa de las Llamas-Moxeke. También, se trata del urbanismo de Pampa de las Llamas-Moxeke y la relación entre este sitio y los otros sitios contemporáneos en el valle, como Taukachi-Konkán y Sechín Alto.

\begin{abstract}
Complex cities developed near groups of monumental mounds in the Casma Valley around $1500 \mathrm{~b}$.C. during the Initial period or Early Formative. To date, the best-known of these sites is Pampa de las Llamas-Moxeke, however, this is only one of several sites in the valley that date to this time period and to the previous time period, the Late Preceramic. This article examines the origins of some characteristics and ideas present in Late Preceramic sites that are further developed in Initial period sites such as Pampa de las Llamas-Moxeke. In addition, the nature of urbanism at Pampa de las Llamas-Moxeke is discussed as well as the relationship of that site with other contemporaneous sites in the valley such as Taukachi-Konkán and Sechín Alto.
\end{abstract}




\section{INTRODUCCIÓN}

$\mathbf{E}$ ste artículo trata de los trabajos arqueológicos realizados por los autores en el valle de Casma entre los años 1980 y 1998. La meta de estos estudios es entender y elucidar el proceso del desarrollo de la sociedad compleja desde el Arcaico Tardío hasta el fin del Formativo Temprano o el Período Inicial. Para hacer esto, los autores realizaron excavaciones arqueológicas en sitios precerámicos, acerámicos y cerámicos, algunos de los cuales se ubican en la costa, mientras que otros se ubican lejos de la zona litoral, en la parte central del valle.

Primero se consideran los resultados de las excavaciones dentro de los sitios de la época del Arcaico Tardío con la finalidad de llamar la atención sobre los rasgos que aparecieron durante este tiempo y que seguieron manifestándose durante el Formativo Temprano. Luego, se trata de los principales sitios del Formativo Temprano, dando cuenta de las diferencias y similitudes entre estos sitios con sus precursores del período Arcaico Tardío. También, se describen los sitios pequeños del Formativo Temprano que funcionaron como satélites costeńos interrelacionados con los grandes sitios ubicados dentro del valle.

\section{HUAYNUNÁ}

Es un sitio que pertenece al período Arcaico Tardío. Cubre un área de 11.5 ha. al borde del litoral de la bahía de Huaynuná, a unos $13 \mathrm{~km}$ al norte de la boca del río Casma (Fig. 1). Hacia el norte y el noreste del sitio, cerca al océano, se puede hallar arquitectura residencial y pública. Al sureste, extensos basurales ocupan los dos tercios del sitio. Estos basurales llegan a una profundidad de $1.5 \mathrm{~m}$. En las excavaciones destinadas a recuperar evidencia de la subsistencia y la economía, se encontraron restos de lúcuma, papa, palta, frijol, mate, camote, achira y algodón. A estos hallazgos se añaden varias especies marinas como peces, mariscos y conchas. La arquitectura residencial, rodeada y tapada por basura, consta de pisos de barro amarillo con muros bajos de uno o dos pedrejones que debieron haber sopor- tado estructuras de totora, cańa u otro material perecedero.

La arquitectura no doméstica de Huaynuná es especialmente significativa porque muestra características en esta época temprana que luego fueron desarrolladas durante la época siguiente: el Formativo Temprano. Dentro de un pequeño montículo de basura, que ha sido remodelado y estabilizado por muros de contención hechos de guijarros. Se encontró un cuarto pequeńo con un fogón ventilado en el centro. La ventilación de realizó por medio de una trinchera, del ancho del fogón, que seguía desde el fogón hasta la entrada (Foto 1) (S. Pozorski y T. Pozorski, 1992a: 34-35; T. Pozorski y S. Pozorski, 1990: 19-21; 1996: 342-343).

En el extremo sur de Huaynuná se ubica un montículo construido sobre la falda de un cerro; los constructores aprovecharon la inclinación del lugar para dar mayor elevación a la estructura sin perder tiempo ni material en el proceso de construcción (Foto 2). El montículo tiene un área de $20 \mathrm{~m}$ por $20 \mathrm{~m}$ y su altura llega a los $8 \mathrm{~m}$. Consiste en una serie de cuatro terrazas paralelas bifurcadas por una escalera central.

No presenta una simetría precisa, pero anticipa el sentido de equilibrio que se presentó en épocas siguientes. La escalera central, que resulta ser un elemento esencial en la arquitectura del Formativo Temprano, conduce hacia un área abierta en la zona del frente. Este espacio pudo funcionar como plaza en donde los habitantes del sitio se reunían para presenciar las actividades, que se llevaron a cabo en la cima del montículo (S. Pozorski y T. Pozorski, 1992b: 849-851; 1990 : 19-22).

\section{PAMPA DE LAS LLAMAS-MOXEKE}

El sitio de Pampa de las Llamas-Moxeke, ubicado en la rama sur del valle de Casma, es una ciudad compleja con arquitectura pública cuidadosamente planificada y zonas residenciales acom- 


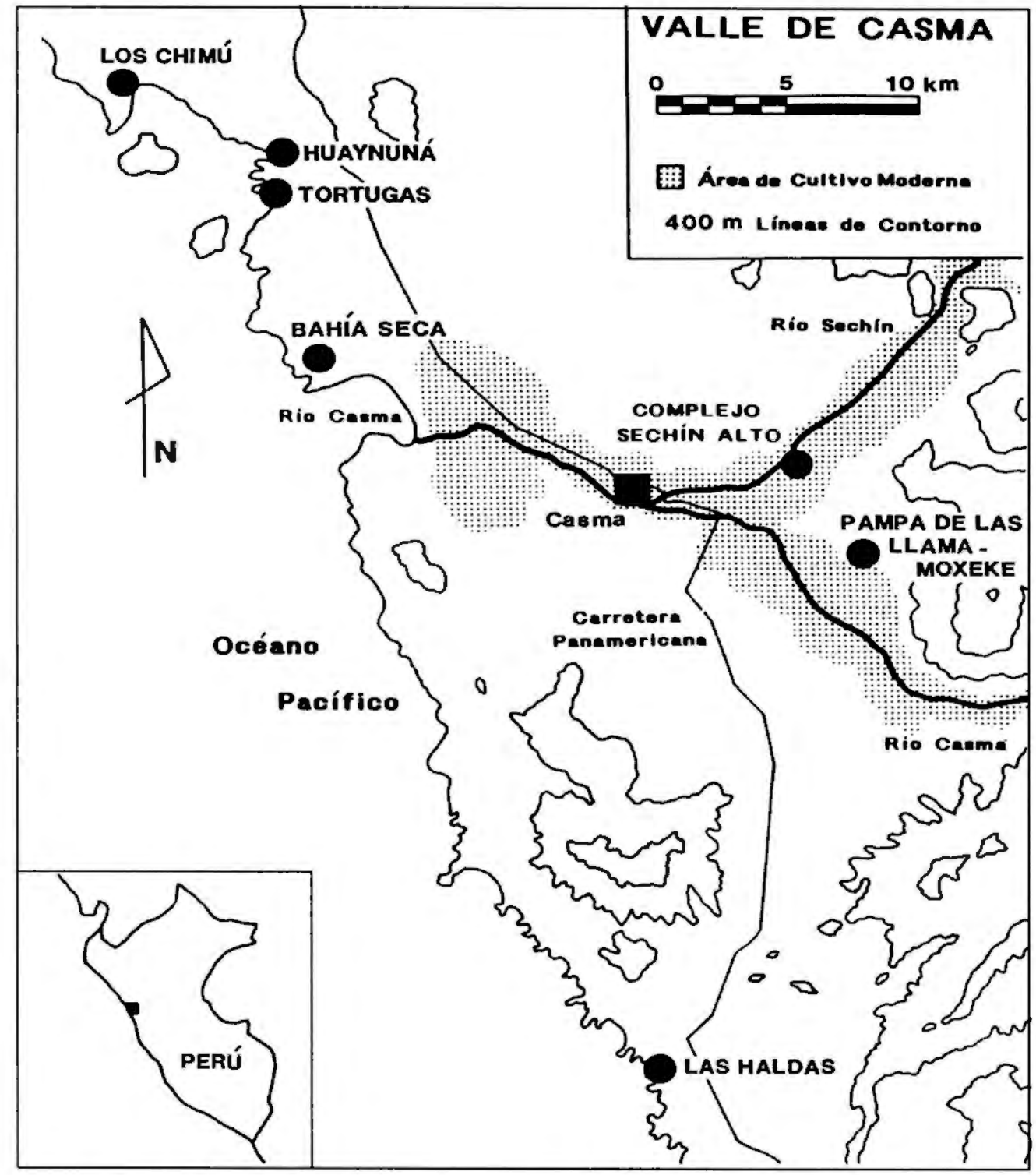

Figura 1. Mapa del valle de Casma mostrando la ubicación de los sitios tempranos.

pañantes (Fig. I). Este sirio fue investigado inicialmente por Middendo if (1973: 219-223) en el siglo XIX. Se realizaron investigaciones más exhaustivas en los años 1937 (Tello, 1956: 44-46) y 1956 (Collier, 1962: 412; Thompson, 1962: 294297). Entre 1980 y 1991, S. Pozorski y T. Pozorski (1986, 1987: 30-45; 1992b:851-859) trabajaron en el sitio, ubicándolo en el período Formativo Temprano. Se basaron en fechas radiocarbónicas de 1600 a 1200 años a.C. (sin calibración'). El establecimiento de sitios como éste dentro de los valles costeños, indicaría (por el tamaño, complejidad y cambio drástico en el patrón de asentamiento) que la agricultura asumió importancia prioritaria en el régimen de subsistencia.
Dos grandes montículos, una serie de plazas inmensas, más de un centenar de montículos y recintos de tamaño intermedio, así como abundantes estructuras residenciales, cubren un área de 220 ha. Los dos montículos principales, Moxeke y Huaca A, se ubican frente a frente y se relacionan entre sí a través de varias plazas abiertas y de esta forma, establecen el eje central de Pampa de las Llamas-Moxeke con una orientación magnética de $\mathrm{N} 41^{\circ} \mathrm{E}$. Los muros de las estructuras de tamaño intermedio y de la mayoría de las estructuras residenciales comparten esta orientación. 


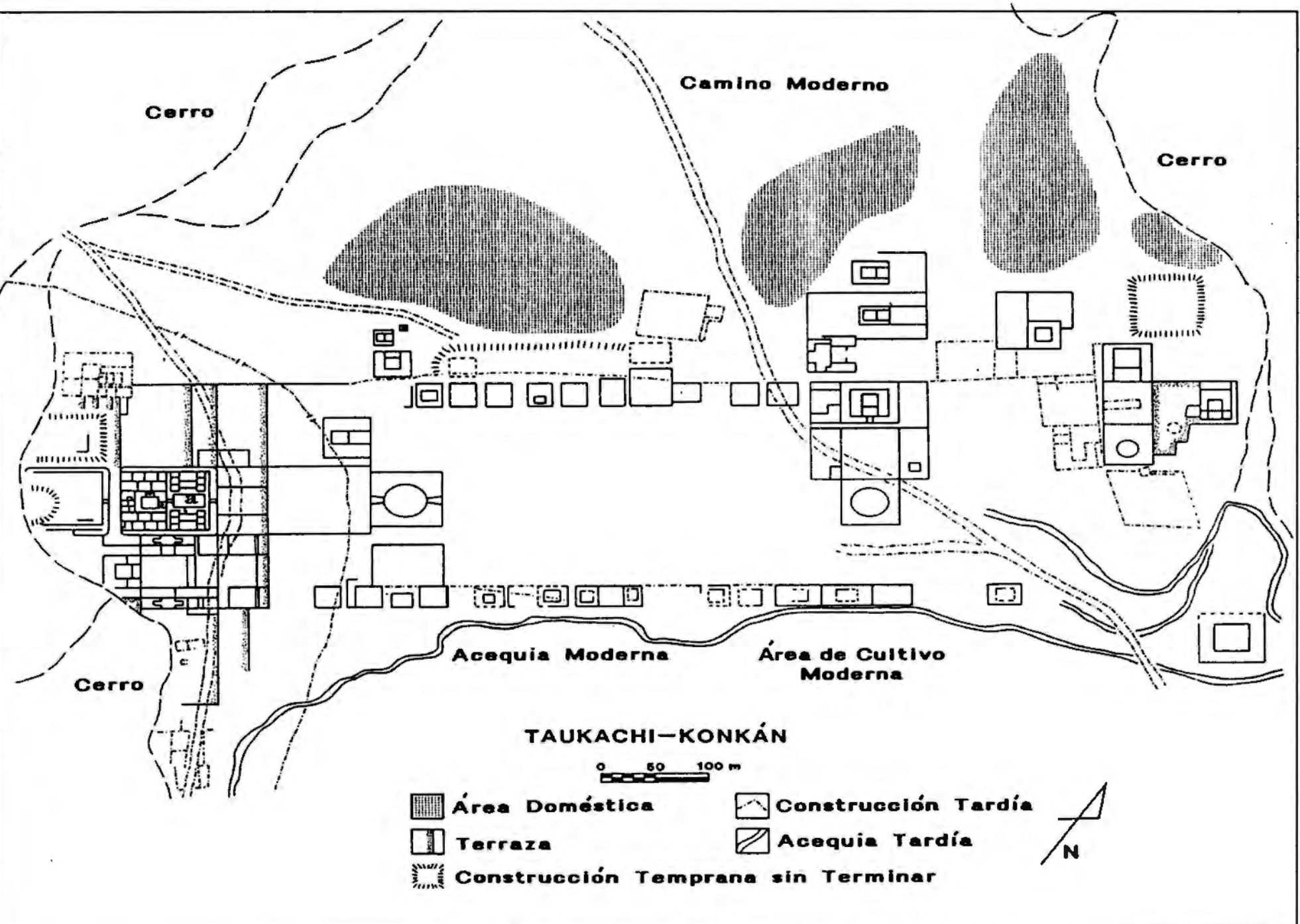

Figura 2. Plano del sitio de Pampa de Las Llamas-Moxeke. 
Foto 1. Vista desde el sur del cuarto con fogón ventilado en Huaynuná.
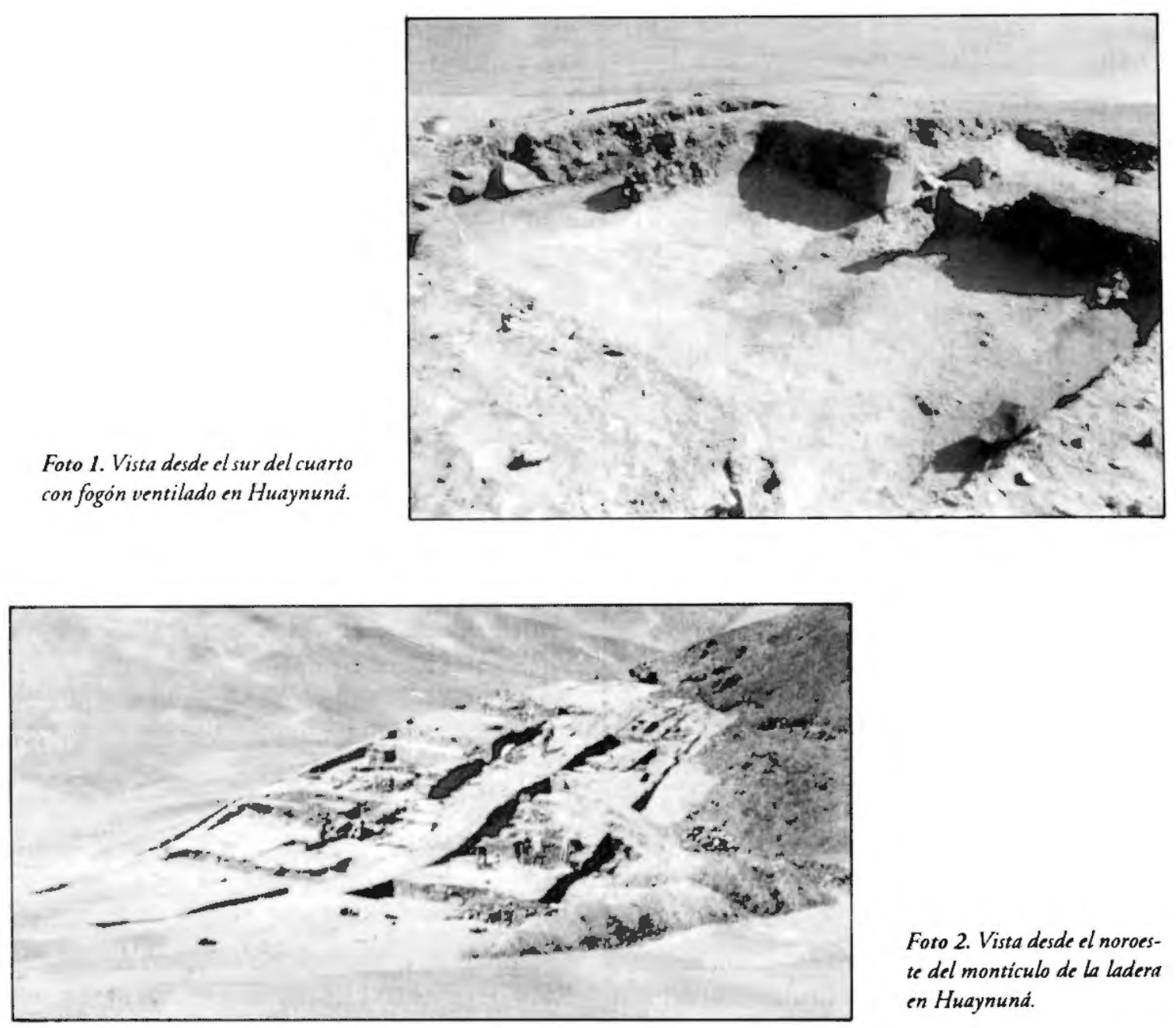

Foto 2. Vista desde el noroeste del monticulo de la ladera en Huaynuná.

\section{la Huaca Moxeke}

La Huaca Moxeke está situada al sur del sitio y, al parecer, funcionaba como edificio ceremonial o religioso (Fig. 2). Esta afirmación se deduce por la presencia de grandes frisos de personajes o dioses, descubiertos por el Dr. Julio C. Tello (1956: 54-66) hace más de 60 años. La ubicación de estos frisos a buena altura, delante del montículo y siguiendo la curva de la esquina redondeada, sugiere una función ritual y pública. Cientos de personas pueden haberse congregado en las grandes plazas alrededor de la Huaca Moxeke para contemplar los frisos y ritos en su cima.

\section{La Huaca A}

La Huaca A se ubica al norte del sitio. Se accede a la cima por medio de escaleras orientadas hacia el norte y sur, ya que la huaca tiene dos entradas principales (Fig. 2, 3a). Hacia el sur se encuentra una serie de plazas rectangulares y la huaca denominada Moxeke. Hacia el norte se ubica una plaza rectangular y otra circular. Ambas entradas están bordeadas por relieves de barro. En la entrada norte pareciera que un par de felinos estuviesen frente a frente. En la entrada sur los relieves han sido erosionados y no se puede distinguir el diseño (Pozorski y T. Pozorski, 1986: 387 389; 1992a: 38-42; T. Pozorski y S. Pozorski 1994: 56-59).

La evidencia arqueológica indica que la Huaca A funcionaba como almacén para objetos de valor y comestibles. En la cima se construyeron cuartos con una distribución muy regular, resultando una simetría de cuatro direcciones. Cada cuarto es una entidad completa, como un mó- 


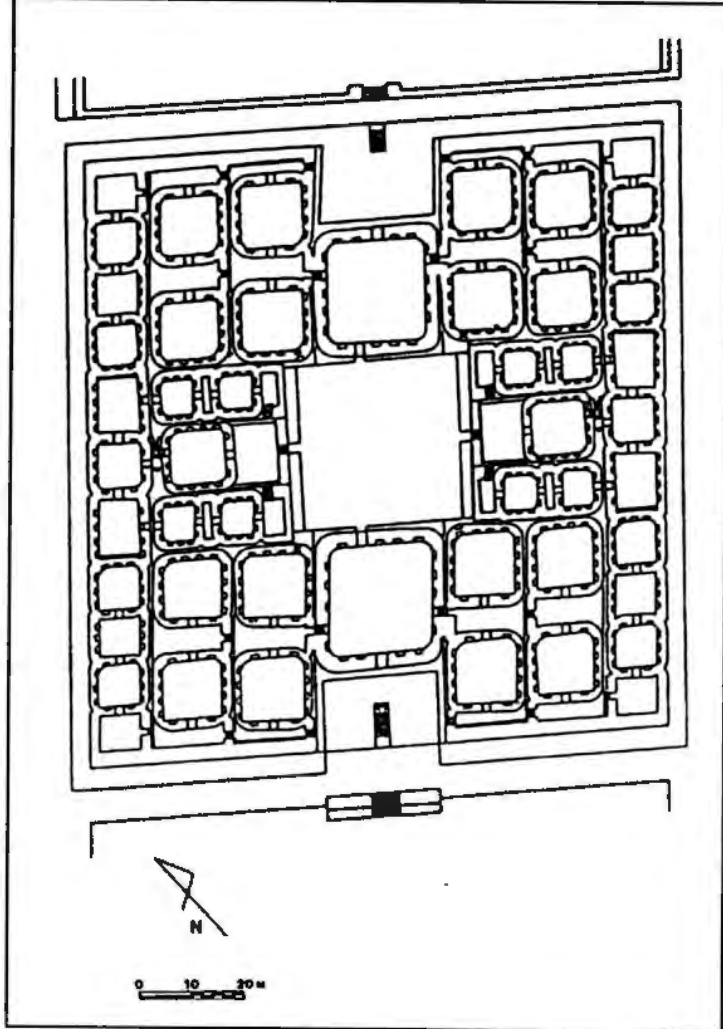

Figura 3a. Plano de la Huaca A de Pampa de las LlamasMoxeke.

dulo de construcción. Estos módulos de construcción, llamados "cuartos cuadrados", exhiben un juego de rasgos que consiste en esquinas redondeadas al exterior, esquinas redondeadas y cuadradas al interior, umbros elevados con barras para restringir el acceso, 9 a 16 nichos altos en los muros y esteras de totora o junco en los pisos. Todas las entradas tienen medidas de control para el acceso. La evidencia de este control está dada por la presencia de un par de nichos pequeńos -uno de poca profundidad y otro de más de $2 \mathrm{~m}$ - que constituían un mecanismo de cerradura, que era operado por una barra de madera que bloqueaba el acceso cuando estaba extendida y permitía el paso cuando se la retiraba (Pozorski y T. Pozorski, 1989: 24-28; 1991: 348350; 52-57).

Se encontraron muy pocos restos arqueológicos en los nichos. Los pequeños fragmentos de tela descubiertos nos indican que, probablemente, se guardaron tejidos, o que otros productos fueron envueltos en ellos, antes de ser colocados en los nichos. Asimismo, éstos contenían polen de plantas comestibles, como la papa, camote, maní, frijol, pallar, palta y algodón.

Otra evidencia del almacenaje de comestibles es la presencia de cientos de huesos de roedores dentro de los nichos, sobre los pisos y las escaleras. Parece ser que estos animales ocuparon los cuartos de la huaca desde el principio, como infestación crónica de las áreas con alimentos. Cuando se abandonó la Huaca A, los roedores reinaron durante un tiempo breve y luego murieron, atrapados en las mismas habitaciones donde habían vivido (S. Pozorski y T. Pozorski, 1991: 348).

\section{Recintos y Monticulos de Tamaño Interme- D10}

Alrededor de la Huaca A se encuentra recintos que representan ejemplares aislados del "cuarto cuadrado" o modular completo con esquinas redondeadas, nichos, umbros elevados y barras de cerradura. En base de su proximidad a la Huaca A, se puede inferir que los ocupantes de estas estructuras tenían algún rol en el control de productos que entraban y salían de la Huaca A.

Entre las estructuras no residenciales del sitio de Pampa de las Llamas-Moxeke, los montículos de tamaño intermedio son los más abundantes.

Se encuentran más de cien ejemplares de estas estructuras en los lados Este y oeste del sitio. La mayoría de ellos son de tamaño intermedio y han sido colocados en filas, alineados con el eje principal del sitio. Los pocos ejemplares que no comparten la orientación del eje principal están dirigidos hacia los caminos que entran a la Pampa de las Llamas-Moxeke desde el Este y el oeste (S. Pozorski y T. Pozorski, 1991: 354-355).

Los montículos de tamaño intermedio son réplicas pequeñas de la Huaca A. Módulos o cuartos cuadrados ocupan el centro, tienen atrios, escaleras $y$, a veces, habitaciones bajas alrededor del "cuarto cuadrado" central. Al igual que los recintos cuadrados vecinos a Huaca $A$, es muy probable que los montículos de tamaño intermedio hayan tenido una función administrativa. Todas las entradas preservadas a una altura suficiente tienen evidencia de control del acceso mediante 
barras de madera. Entre los artefactos recuperados de los montículos de tamaño intermedio hay sellos hechos de cerámica que todavía tienen restos del pigmento rojo en sus indentaciones. Sus ocupantes pueden haber participado en el sistema burocrático que regulaba la producción, almacenaje y distribución de los comestibles y otros objetos de valor que llenaban los nichos y los cuartos modulares de la Huaca A.

\section{Fogones con Ventiladores}

En lugares aledaños a la arquitectura de tamaño intermedio se encontraron tres fogones con ventiladores. El ejemplar más simple consta de un fogón central circular bordeado con piedras que se ubica en un "cuarto cuadrado" con esquinas redondeadas. Este fogón está ventilado por medio de una trinchera que lo recorre desde el centro a la entrada. En este aspecto es muy similar al fogón ventilado de Huaynuná. Otro fogón, que posiblemente haya servido del mismo modo se encuentra en el "cuarto cuadrado" de un montículo de tamaño intermedio que ha sido remodelado. Generalmente, los montículos de tamaño intermedio no contienen fogones, pero en este caso, un fogón de buen tamaño ha sido construido en el centro del "cuarto cuadrado" y sus entradas han sido selladas.

El fogón ventilado más elaborado consta de un cuarto redondo construido encima de una plataforma rectangular. El fogón se ubica en el centro del cuarto redondo y los ventiladores corren en cuatro direcciones debajo del piso del cuarto y de la plataforma hacia los cuatro lados de ésta (Foto 3)(T. Pozorski y S. Pozorski, 1996: 344$345)$.

\section{Arquitectura Residencial.}

Gran cantidad de restos de arquitectura residencial de status elevado y bajo se encontró en los lados Este y oeste de Pampa de las LlamasMoxeke. Las estructuras residenciales de los habitantes de status elevado se ubican cerca de la arquitectura intermedia no doméstica, tienen altos muros de piedra construidos de acuerdo a la orientación del eje del sitio. Dentro de estas habitaciones hay fogones grandes y elaborados $y$, a veces, depósitos forrados con piedra debajo de los pisos (S. Pozorski y T. Pozorski, 1986: 395397).

Las estructuras residenciales de los habitantes de bajo status social se encuentran en la zona Este del sitio. Los restos de estas casas comprende filas de piedra, que conforman la base sobre la que se construyó una estructura de caña brava o quincha. Estos grupos de cuartos interconectados no siguen la orientación establecida del sitio y sus fogones son pequeños y simples. Dentro de la zona de arquitectura de bajo status a veces se encuentran algunos ejemplares aislados de cuartos modulares con altas paredes de piedra. Estas unidades arquitectónicas pueden haber servido como nudos administrativos dentro de la zona residencial para regular la producción a nivel doméstico o del grupo familiar como la fábrica de textiles.

Foto 3. Vista desde el noroeste del cuarto circular con fogón ventilado ubicado en el lado oeste de Pampa de las Llamas-Moxeke.

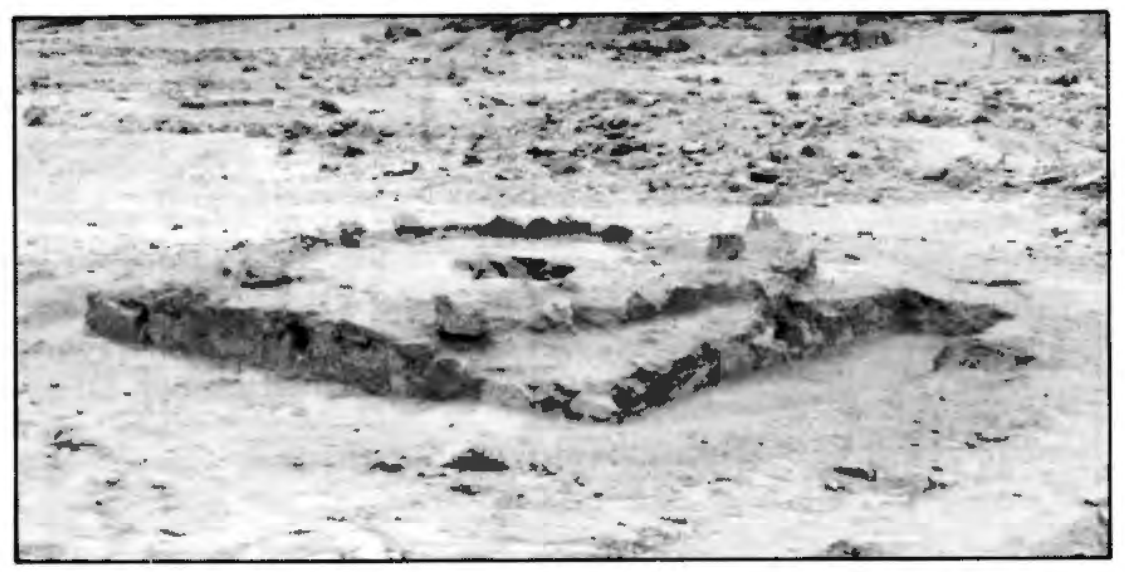




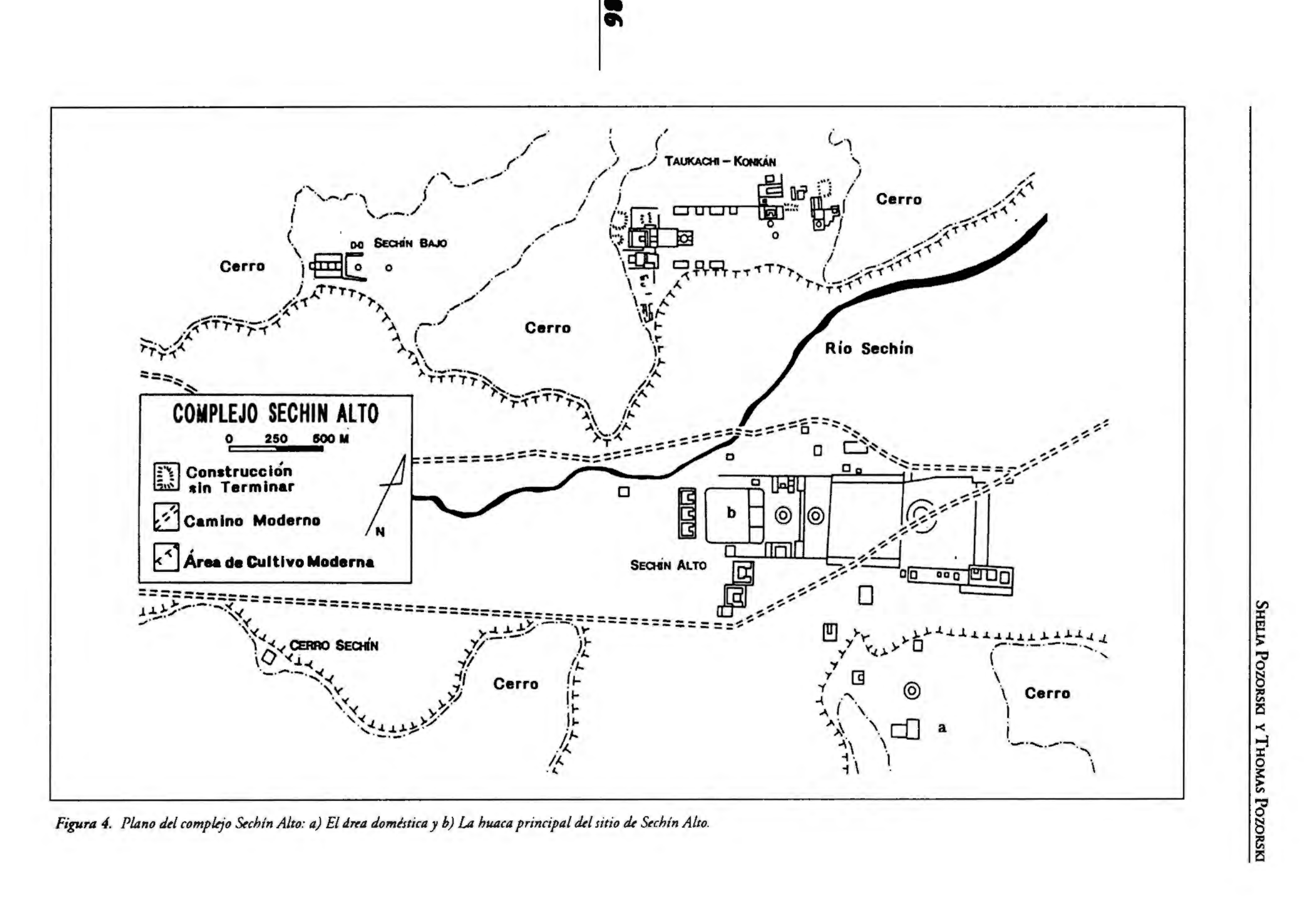




\section{Artefactos}

Los artefactos de Pampa de las Llamas-Moxeke incluyen cerámica simple, figurinas, textiles y morteros o tazones de piedra. La forma principal de la cerámica es la olla sin cuello, sin decoración o con decoración muy simple de puntadas largas y profundas conformando una fila en el hombro de la vasija. También se encuentra en abundancia, en la Pampa de las Llamas-Moxeke, el tazón o mortero de piedra con su pistadero acompañante. Se utilizó, principalmente, basalto y granodiorita para fabricar vasijas de 15 a $28 \mathrm{~cm}$ de diámetro cuyos lados, casi rectos, tienen una altura que fluctúa entre los 15 y $30 \mathrm{~cm}$. Algunos ejemplares que no se hallan con frecuencia, han sido decorados con incidiones, pero hasta ahora no se ha encontrado ningún diseño completo (S. Pozorski y T. Pozorski, en prensa: Figuras 14-15; S. Pozorski y T. Pozorski, 1992: 165-168, figuras 2-5, 7-8)

Las figurillas, también de cerámica, son semejantes a un ejemplar descubierto en el sitio de

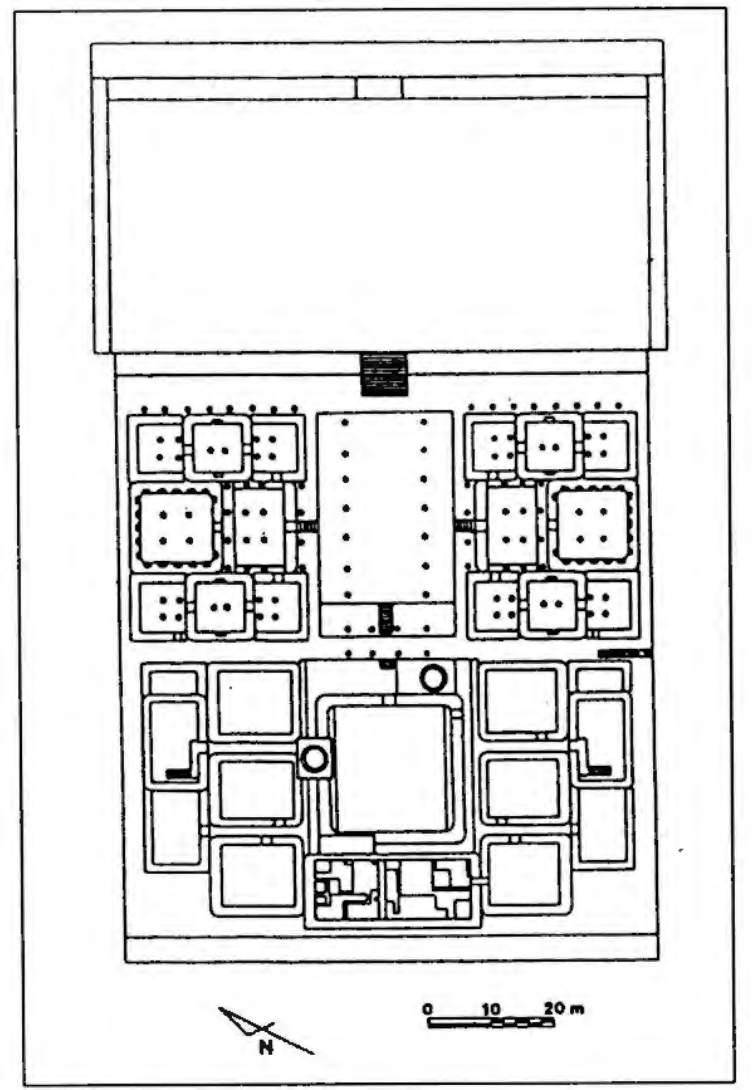

Figura 3b. Huaca de las Columnas de Taukachi-Konkán.
Las Haldas (Ishida et al., 1960: 196, 446, figuras 60-61; S. Pozorski y T. Pozorski, en prensa: Figuras 11-13). La mayoría fue elaborada con barro sólido. Esta figurillas presentan un ser antropomorfo de pie, con las piernas paralelas y juntas, los brazos sobre el pecho pero no cruzados. No tiene evidencia de ropa ni de características físicas sexuales. Algunas tienen un collar con decoración geométrica por incisión. En la cabeza presentan tocados de forma cónica o cabello peinado y arreglado en un estilo muy alto, $y$ puede ser que estas características sean las mismas que se ven en las gorras y el cabello de las figuras de Cerro Sechín (Samaniego y Cárdenas, 1995: 267, 272, 276; Tello, 1956: 152, 156, 161). Debajo de los brazos, el cuerpo ha sido perforado, dejando un par de huecos pequeños que podrían haber servido para amarrar y mantener las figurillas suspendidas.

\section{TAUKACHI-KONKÁN}

El sitio de Taukachi-Konkán es conocido por estudios de reconocimiento hechos por más de 60 años (Fung y Williams, 1977: 116-118; S. Pozorski, 1987: 22; S. Pozorski y T. Pozorski 1987: 75-78; Tello 1956: 75; Thompson 1961: 211217). Taukachi-Konkán junto con Sechín Alto y Sechín Bajo componen el Complejo Sechín Alto, un grupo de cuatro sitios interrelacionados que domina el valle de Sechín (véase Figs. 4-5) (S. Pozorski y T. Pozorski 1987: 114-117, 1992b: $860-861)$. Los sitios comparten rasgos arquitectónicos, artefactos, semejanzas de configuración y una orientación de $\mathrm{E} 32^{\circ} \mathrm{N}$. Los autores escogieron el sitio de Taukachi-Konkán para investigarlo debido a dos razones: 1) la ubicación del sitio está fuera de los límites de las tierras destinadas al cultivo lo que implica una buena preservación; y 2) el plano del sitio indica posibles conexiones con el sitio de Pampa de las Llamas-Moxeke, en la rama sur del valle de Casma. Los autores realizaron excavaciones en el sitio de Taukachi-Konkán durante tres campañas entre los años 1992-1994.

El sitio de Taukachi-Konkán tiene varios montículos de buen tamaño, algunos asociados a plazas circulares. Una de las huacas principales domina el sitio y establece la orientación del eje principal de $\mathrm{E} 32^{\circ} \mathrm{N}$. En los lados norte y sur hay filas 


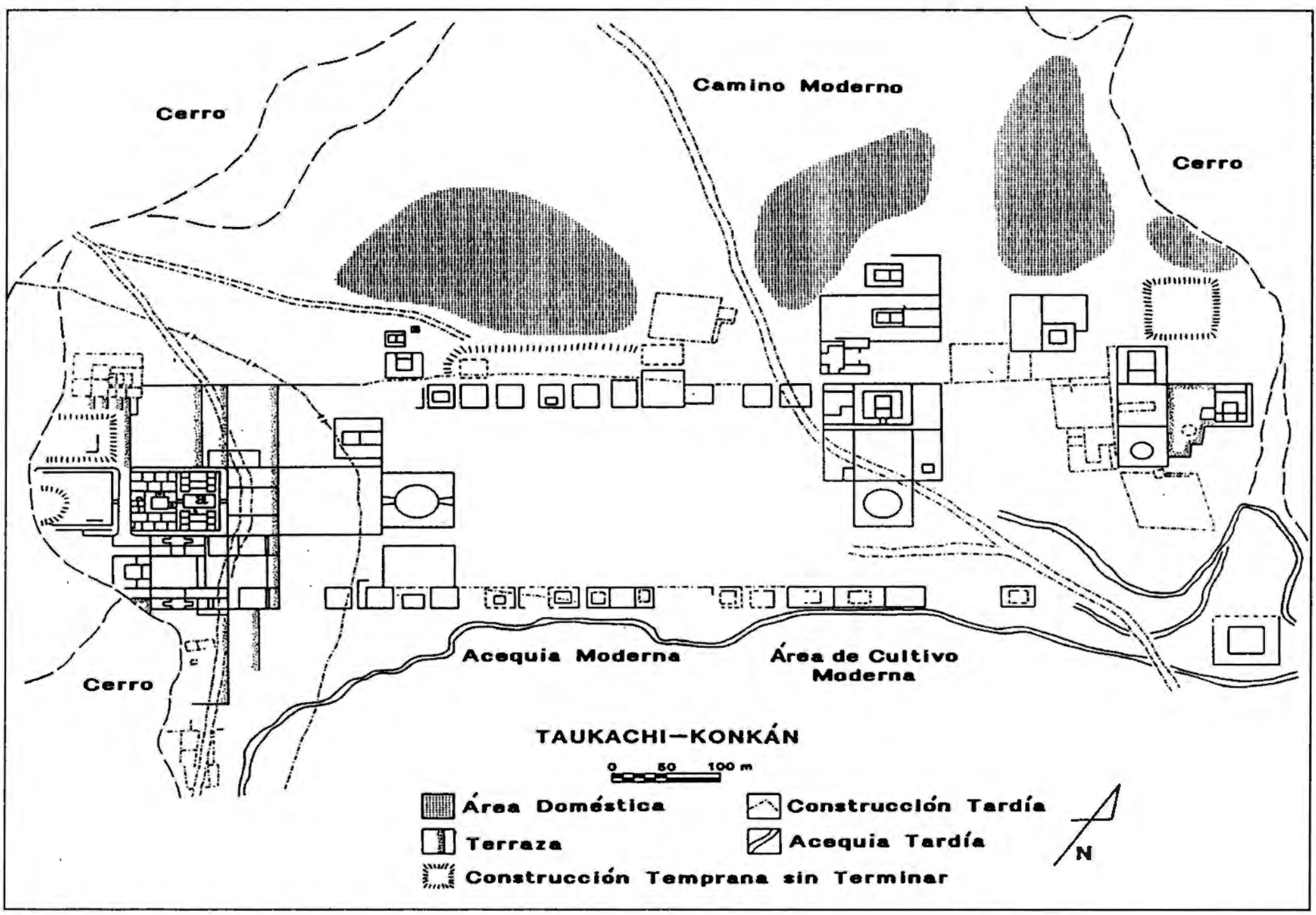

Figura 5. Plano de Taukachi-Konkan: a) La Huaca de las Columnas. 
de montículos de tamaño intermedio y hacia el norte existen restos dispersos de una ocupación doméstica.

\section{la Huaca de las Columnas}

Las investigaciones arqueológicas en el sitio de Taukachi-Konkán se concentraron en la huaca principal, que los autores han denominado Huaca de las Columnas (Fig. 3b). Los resultados de las investigaciones indican que la huaca funcionó como palacio o residencia real con sectores públicos y residenciales. El nombre viene de la abundancia de columnas en el sector Este, más de un centenar, que probablemente soportaban un techo de cańa o totora. El techo puede haber protegido a los ocupantes del sol y también puede haber asegurado su privacía, bloqueando la vista desde los cerros altos al oeste de la huaca.

Las columnas se puede evidenciar por la presencia de amplios pozos forrados con piedras. Dentro de los pozos se encontraron restos de cańas o ramas delgadas amarradas con soga de junco. Este "poste" compuesto de material orgánico formó el soporte central de la columna y por último fue cubierto con barro y finamente enlucido. La madera y la caña recolectadas de los pozos de la columnas y el carbón procedente de fogones ubicados en distintos sectores han sido utilizados para conseguir fechados radiocarbónicos. Los resultados varían entre los 1600 y 1200 años a.C. (sin calibración) (véase Tabla 1).

Hacia el Este, los dos tercios de la Huaca de las Columnas presentan una simetría precisa, es muy limpia, tiene un fino enlucido y parece haber sido el sector público de la huaca. En este sector los "cuartos cuadrados" o modulares presentan las mismas características a los hallados en Pampa de las Llamas-Moxeke: Esquinas redondeadas, nichos, umbros elevados y entradas restringidas por barras. En un contexto como la Huaca de las Columnas, los cuartos cuadrados parecen haber servido como repositorios para materiales de valor, que se daban y recibían como parte del rol social del personaje que ocupaba la huaca (Foto 4). Otros cuartos, en el sector Este, son semejantes a los cuartos modulares por su forma, pero los pisos de los nichos son mucho más bajos. Estos cuartos con nichos bajos, como si fueran asientos, probablemente fueron usados para reuniones pequeñas entre personas de importancia.

El sector de la Huaca de las Columnas, ubicado en el extremo oeste parece más irregular y contiene abundantes restos de alimentos. Parece que sirvió como residencia para la gente que ocupó la huaca (Foto 5). La zona residencial contiene plataformas bajas y medianas destinadas a actividades domésticas y cuartos pequeños para almacenaje, pero falta evidencia de la preparación de los alimentos.

La preparación de la comida no se llevó a cabo en la cima de la huaca sino dentro de un complejo arquitectónico ubicado hacia el sur. Esta estructura, ocupada por el personal que sirvió al líder más poderoso, contiene abundante evidencia de fogones y también lo que puede haber sido un horno para pachamanca. El sector de servicio y la cima se comunican entre sí a través de una escalera estrecha y escondida que se encuentra en el lado sur.

\section{Fogones CON Ventiladores}

Al borde de un patio grande cuadrado, en el sector central de la Huaca de las Columnas, se encontraron dos fogones con ventiladores que conectan Taukachi-Konkán con Pampa de las Llamas-Moxeke y su antecedente Huaynuná. El primer fogón consta de un cuarto circular que descansa sobre una plataforma rectangular, la cual se ventiló por medio de una trinchera que conduce hacia lo que probablemente era la entrada ( $T$. Pozorski y S. Pozorski, 1996: 346).

El otro fogón con ventiladores en la cima de la huaca, se ubica en el lado norte del patio cuadrado (Foto G). Este fogón es una réplica del que se encuentra en Pampa de las Llamas-Moxeke. Consta de un cuarto circular situado sobre una plataforma rectangular delimitada por piedras. Tiene cuatro ventiladores que atraviesan por debajo el piso de la plataforma, desde el fogón central hacia las cuatro direcciones. En el desmonte extraído de la estructura, durante las excavaciones, se encontraron varios fragmentos del enlucido (al- 
gunos con impresiones de los muros y los techos de quincha y otros con manchas negras que resultaron del humo producido por el fogón central). La tercera habitación donde se encontró un fogón con ventiladores fue en el sitio de TaukachiKonkán. También se ubica sobre una plataforma rectangular con cuatro ventiladores debajo del piso pero está ubicado cerca de la fila norte de montículos de tamaño intermedio.

\section{Artefactos}

La mayoría de los artefactos recuperados en Taukachi-Konkán es muy semejante a los artefactos procedentes de Pampa de las LlamasMoxeke. Los artefactos más notables incluyen tazones o morteros de piedra, figurillas de cerámica y fragmentos de ollas sin cuello (sin decoración o con una decoración muy simple de puntadas largas y profundas, arregladas en una fila). También, se encontraron tiestos de cerámica con puntadas frecuentes y poco profundas colocadas en zonas que representan un tipo de cerámica bien conocido del sitio costeño de Las Haldas.

\section{SECHÍN ALTO}

Antes de 1995, se conocía el sitio de Sechín Alto por reconocimientos efectuados por Fung $y$ Williams (1977: 112-116), Kosok (1965: 214 215), S. Pozorski y T. Pozorski (1987: 71-75), Tello (1956: 79-82), Thompson (1962: 294, 1964: 207-208) y por algunos pozos de prueba realizados en 1956 (Carlevato, 1979: 29-39, Collier, 1962: 411). Los autores comenzaron las excavaciones en el sitio de Sechín Alto en el año 1995 y todavía están en proceso. Este sitio, el más grande del complejo Sechín Alto, consta de un grupo central de montículos y plazas acompañadas por otros montículos, plazas y áreas domésticas o residenciales en las zonas circunvecinas.

Dentro de las zonas domésticas se encontraron basurales profundos con evidencia amplia de plantas comestibles y restos abundantes de productos marinos. También se recuperaron de los basurales fragmentos de cerámica y de figurillas, y se encontraron algunas evidencias de estructuras domésticas.

\section{La Huaca Principal de Sechín Alto}

La Huaca Principal de Sechín Alto se orienta hacia el Este y establece la orientación del sitio, en la cual se incluye la serie de plazas que se extiende más de un kilómetro hacia el Este, los montículos que forman los bordes norte y sur de las plazas y otros montículos cerca a la huaca principal. Dos de las plazas alineadas contienen plazas circulares hundidas y otros montículos aislados están asociados con plazas circulares. Las excavaciones en la huaca principal comenzaron en el año 1995 y todavía están en proceso (Fig. G). Estas investigaciones se han concentrado en tres sectores: en las escaleras y los atrios ubicados al Este para elucidar el patrón de acceso principal; en la zona de adobes cónicos para descubrir su función y también para investigar la relación de esta zona y el resto de la huaca; $y$ en un cuarto profundo cerca de la zona de adobes cónicos para explorar la naturaleza de un sector arquitectónico de la fase penúltima de construcción.

En realidad, las investigaciones en la Huaca Principal de Sechín han sido afectadas profundamente por la reocupación de ésta durante el Formativo Tardío u Horizonte Temprano. La gente de esta época construyó una aldea encima del montículo. Nivelaron la arquitectura, quitando las piedras de los muros del Formativo Temprano. La zona de adobes cónicos como fuente de barro para el mortero y el enlucido. También, durante esta ocupación post-primaria, los habitantes depositaron una capa gruesa de basura sobre casi toda la cima de la huaca y desecharon la basura adicional hacia el Este, cubriendo las escaleras principales de la ocupación primaria. Otro resultado de la reutilización de la huaca principal de Sechín Alto es que casi toda la cerámica encontrada en la superficie pertenece al Formativo Tardío y puede dar una indicaciǒn falsa con respecto a la fecha del sitio Sechín Alto. Una muestra de carbón recogida de un fogón intrusivo de la ocupación del Formativo Tardío dio una fecha radiocarbónica de $260+60$ años a.C. (Beta110591) para la reocupación de la huaca (Véase Tabla 1).

La investigación del patrón de acceso a la cima de la huaca se inició con la excavación de la esca- 
Foto 4. Vista desde el sur de un "cuarto cuadrado" dentro de la ala sur del atrio de la Huaca de las Columnas.
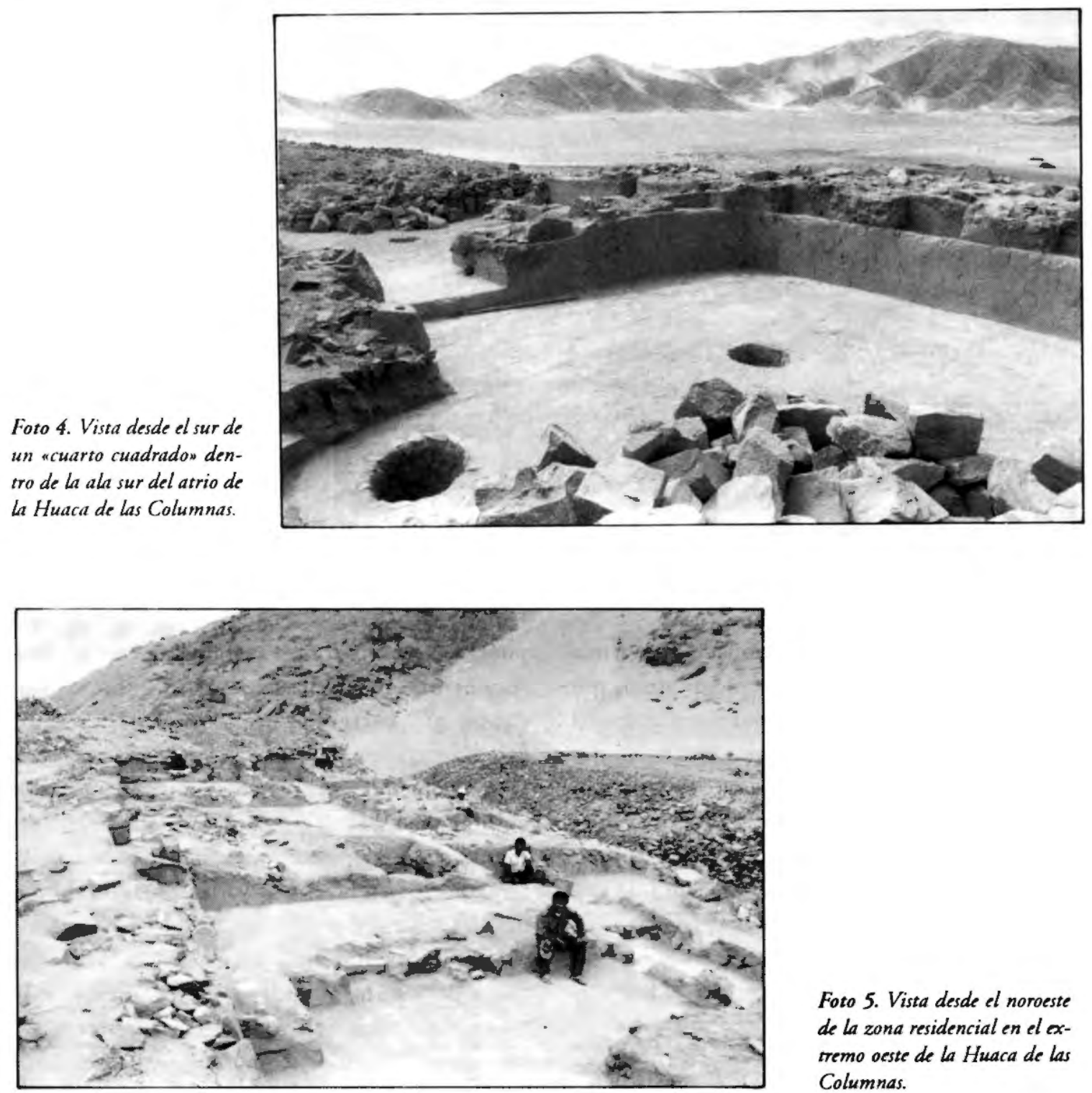

Foto 5. Vista desde el noroeste de La zona residencial en el $x$ tremo oeste de la Huaca de las Columnas.

lera más baja que conduce desde el nivel actual de la superficie a un descanso y luego al atrio principal. De allí, cuatro juegos adicionales de escaleras ascienden a la cima de la huaca, que tiene una altura de $35 \mathrm{~m}$. La última escalera llega a su entrada principal mide $4.7 \mathrm{~m}$ de ancho y $4.7 \mathrm{~m}$ de profundidad, penetrando un muro que, por el ancho de su base, puede haber tenido una altura mayor a los $5 \mathrm{~m}$. Para construir la entrada, se usaron grandes piedras trabajadas para formar esquinas precisas. Las piedras más largas miden más de $1.6 \mathrm{~m}$ y se ubicaron en forma paralela a los lados de la entrada.

Otras excavaciones se concentraron en la zona central de adobes cónicos. Como se mencionó antes, esta zona ha sido explotada por los pobladores del Formativo Tardío como cantera para obtener materiales para la elaboración de morteros y enlucidos. En ciertos lugares se pueden ver las huellas de sus implementos de excavación. Más tarde, la zona fue utilizada como cementerio por los pobladores del Horizonte Medio. Luego, los huaqueros robaron los entierros intrusivos, dejando dispersos los restos óseos y los artefactos. Toda la zona ha sido afectada por las lluvias producidas durante los eventos del fenómeno de El Niño, ya que el barro se deshace fácilmente y el agua se empoza en las áreas bajas.

Sin embargo, las excavaciones que se concentraron en la zona central de adobes cónicos re- 


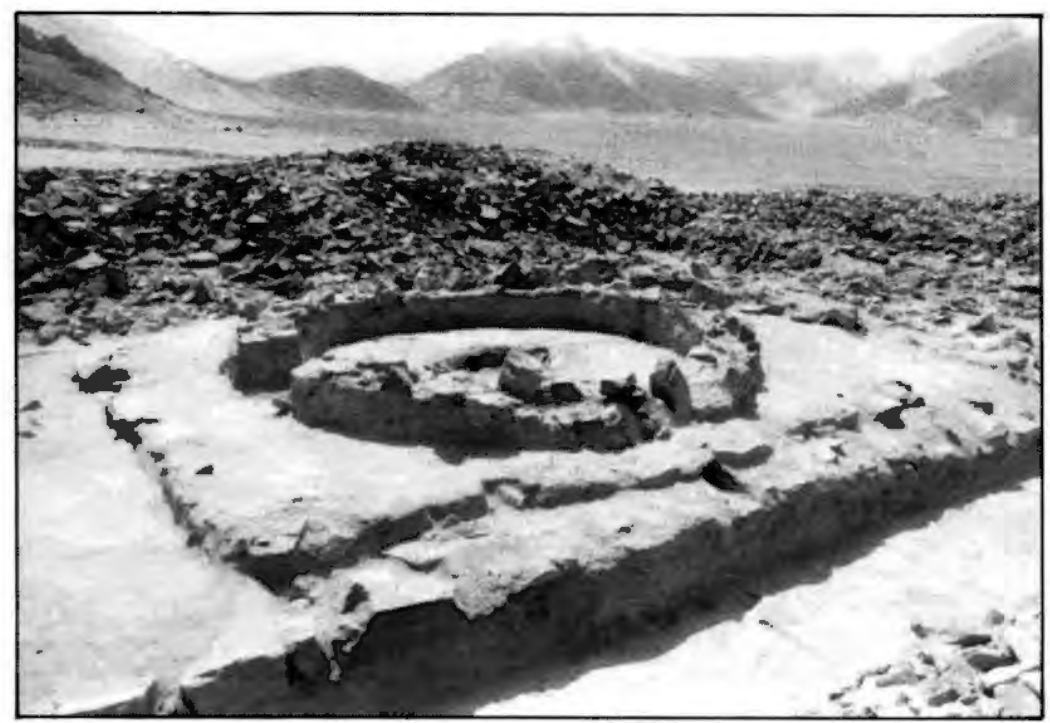

Foto 6. Vista desde el sur de un cuarto circular con fogón ventilado ubicado en el lado norte del patio cuadrado encima de la Huaca de las Columnas. velaron que puede haber funcionado como una zona sagrada. La zona sagrada tiene su entrada por el lado sur y consiste de un corredor o plataforma baja de adobes cónicos reforzados por columnas de piedra que conduce a un cuarto elevado con relieves en los lados Este y oeste. Los Relieves fueron encontrados sobre las caras anteriores y posteriores de una serie de columnas, que han sido casi niveladas durante la reocupación del Formativo Tardío y las caras anteriores han sufrido los graves efectos de la erosión. Pero en el área protegida, los relieves están en mejores condiciones y se pueden apreciar los colores (rojo, azul, blanco, negro y gris) aunque no se puede interpretar el diseño. Las columnas fueron reforzadas con postes hechos de caña y ramas pequeñas de madera amarradas con sogas de junco. De las muestras de estos materiales orgánicos se obtuvieron fechas radíocarbónicas que indican una ocupación perteneciente al Formativo Temprano (véase Tabla I).

Las invesrigaciones en el "cuarto profundo" revelaron la magnitud de la arquitectura temprana de la huaca y mostraron la evidencia de conexiones arquitectónicas con Pampa de las Llamas-Moxeke y Taukachi-Konkán. Dichas excavaciones descubrieron una secuencia de plataformas superpuestas hechas de adobes cónicos. La plataforma inferior tiene $6 \mathrm{~m}$ de altura y la superficie todavía tiene restos de pintura roja y también evidencias de graffiti prehispánicos. Des- pués, se construyó otra plataforma con pintura roja, pero también con una banda de pintura blanca en su margen superior. Dos cuartos interconectados descansan sobre la plataforma rojo y blanco. Uno es rectangular o cuadrado con esquinas cuadradas, y el otro es cuadrado con esquinas redondeadas, replicando la unidad modular conocida en las huacas principales de Pampa de las Llamas-Moxeke y Taukachi-Konkán (Fig. 7 ). Se puede notar pintura amarilla en la cara exterior del cuarto modular y pintura negra en la cara exterior del otro cuarto. Las plataformas y los cuartos pintados descubiertos en el "cuarto profundo" no pertenecen a la última fase de uso de la huaca en el Formativo Temprano. Probablemente, pertenecen a la penúltima fase porque se encontraron debajo de unos $12 \mathrm{~m}$ de relleno, el que forma la base de la última construcción primaria de la huaca. Muestras de carbón recolectadas de varios contextos asociados con la arquitectura pintada que fueron sometidas a datación radiocarbónica dieron como resultado fechas que pertenecen al Formativo Temprano (véase Tabla 1).

\section{Artefactos}

Los artefactos procedentes del sitio de Sechín Alto incluyen ejemplares del Formativo Temprano y Tardío. Los pobladores que reocuparon la cima de la huaca durante el Formativo Tardío dejaron 
rasgos típicos de su tiempo: fragmentos de tazones decorados con círculos y puntos, antaras de cerámica y puntas de pizarra.

Las excavaciones en los basurales de la zona residencial o doméstica del Formativo Temprano mostraron buenas cantidades de fragmentos de figurillas muy parecidas a los ejemplares de Pampa de las Llamas-Moxeke, Taukachi-Konkán y Las Haldas. También las investigaciones en los basurales permitieron encontrar una cantidad regular de cerámica de los tipos encontrados en Pampa de las Llamas-Moxeke y Las Haldas. Los resultados de las excavaciones en la cima de la huaca indican que la cerámica típica de Pampa de las Llamas-Moxeke tiene una posición estratigráfica inferior a la cerámica típica de Las Haldas.

\section{CONCLUSIONES}

En base a las excavaciones de los sitios del Arcaico y el Formativo Temprano efectuadas en el valle de Casma y los alrededores, es posible hablar con más confianza del desarrollo temprano de la zona. Los resultados de las investigaciones de los sitos de Pampa de las Llamas-Moxeke, TaukachiKonkán y Sechín Alto revelan conexiones entre los sitios con respecto a artefactos, la arquitectura y las fechas radiocarbónicas. La cerámica hallada pertenece al mismo tipo que la encontrada en los sitios de Pampa de las Llamas-Moxeke, Taukachi-Konkán y Sechín Alto. El mismo tipo de figurilla aparece en los tres sitios y en Las Haldas. En cambio, la cerámica del tipo Las Haldas se conoce en los sitios de TaukachiKonkán y Sechín Alto, pero no en Pampa de las Llamas-Moxeke. Los resultados de las excavaciones en la huaca principal de Sechín sugieren que dentro del valle de Casma, la cerámica del tipo Las Haldas apareció después de la cerámica del tipo Pampa de las Llamas.

Aspectos generales como la planificación de los sitios a base de un eje central establecido por uno o dos huacas principales; la asociación de las huacas principales con plazas cuadradas y circu-

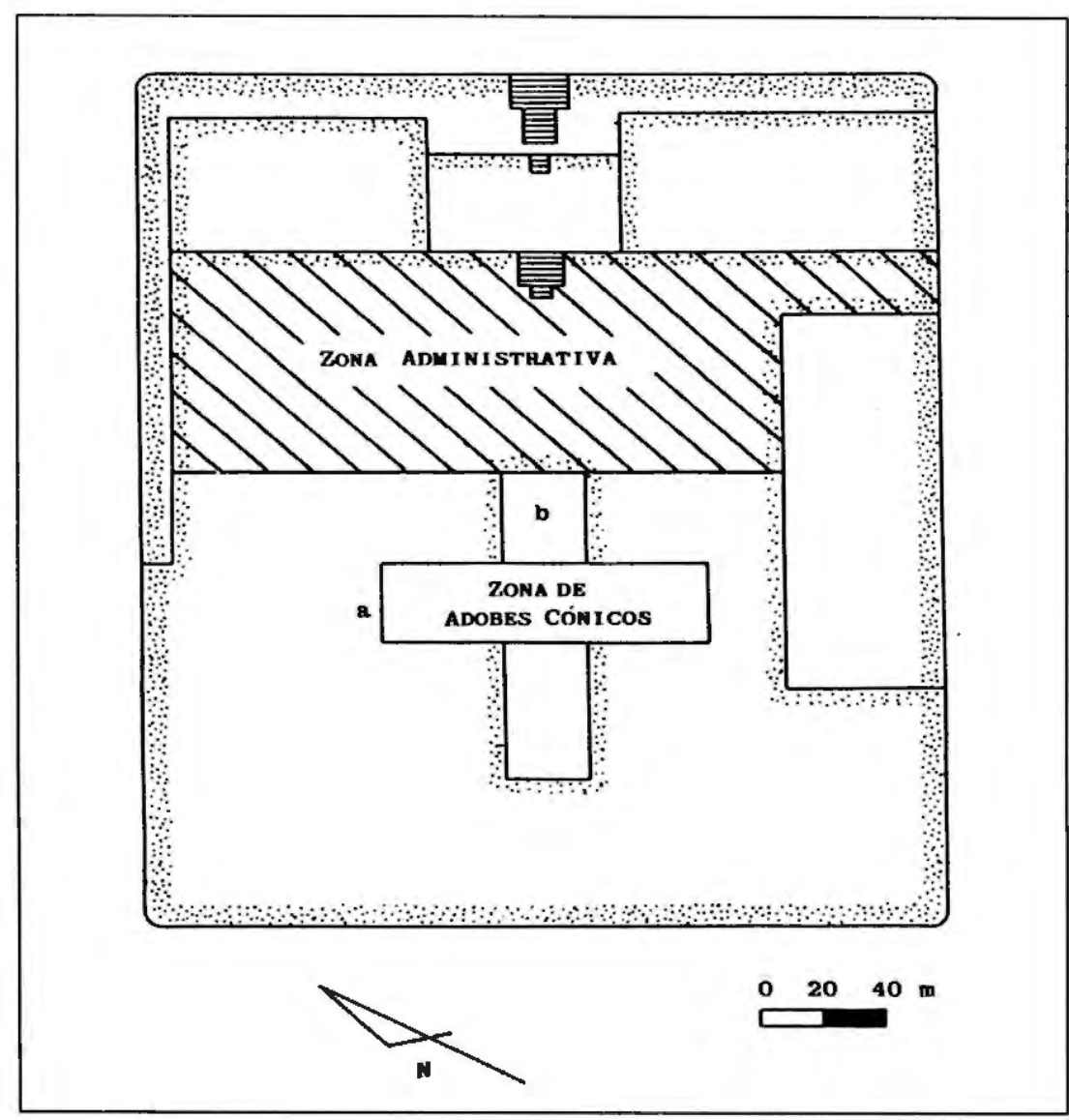

Figura 6. Plano de La huaca principal del sitio de Senchin Alto: a) Los relieves pintados; b) El «cuarto profundow. 


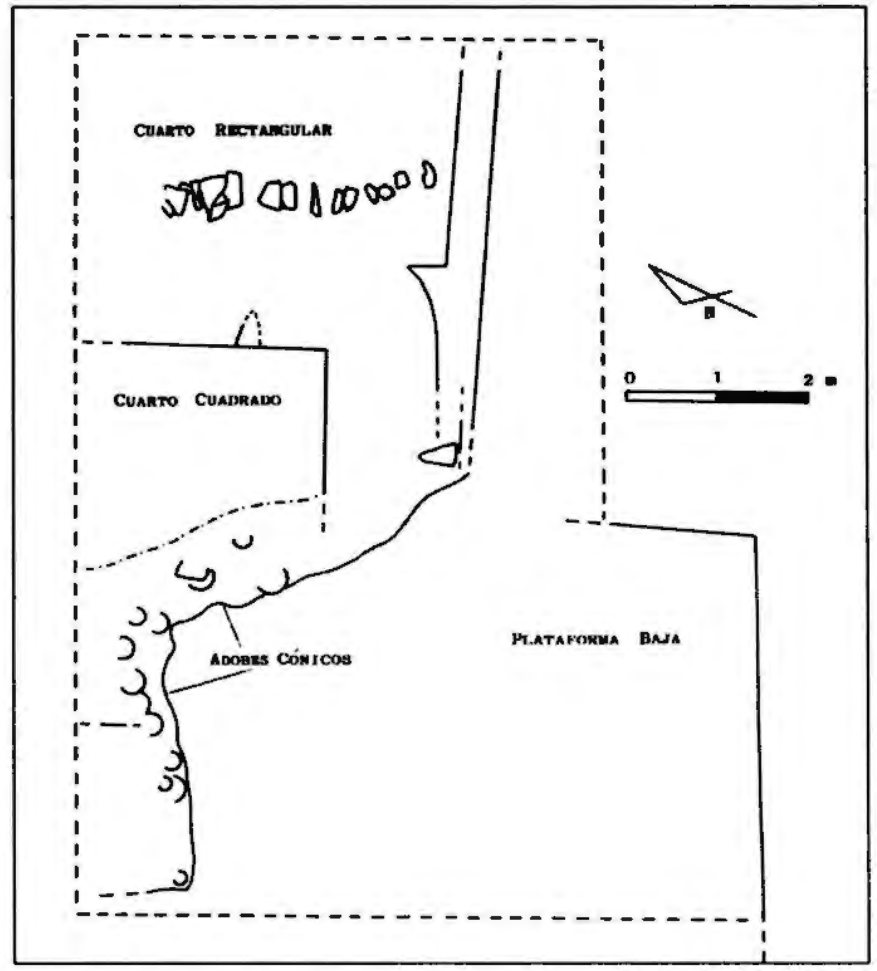

Figura 7. Plano del acuarto cuadradon descubierto como parte de la fase penúltima de la construcción dentro del "cuarto profundo" encima de la huaca principal del sitio de Sechin Alto.

lares; y la presencia de montículos de tamaño intermedio también caracterizan los tres sitios. Otro rasgo arquitectónico que tiene gran importancia como evidencia de las conexiones entre los sitios, es el "cuarto cuadrado" con esquinas redondeadas o el cuarto modular, reconocido primero en el sitio de Pampa de las Llamas-Moxeke, y también en Taukachi-Konkán y Sechín Alto. En el sitio de Pampa de las Llamas-Moxeke (el de mejor preservación), el cuarto modular, ubicado en la cima de la Huaca $A$, es el componente arquitetónico principal.

En el sitio Taukachi-Konkán, se encontró el cuarto modular en el sector público de la Huaca de las Columnas. En este contexto, es probable que el cuarto modular funcionara como almacén de los materiales de valor, que daban o recibían los habitantes de la huaca, utilizadas como pequeñas salas de reunión. No se sabe mucho sobre el contexto del cuarto modular descubierto en la huaca principal de Sechín Alto, pero se puede postular que esta huaca y especialmente la zona en que se encontró el cuarto modular, tuvieron una función administrativa. Los datos que se es- tán acumulando sobre los contextos de los cuartos modulares, hacen presumir que la presencia . de este rasgo arquitectónico sea una indicación de las conexiones y la contemporaneidad de los sitios casmeńos del Formativo Temprano, también se puede argumentar la relación existente entre las actividades administrativas y un determinado patrón arquitectónico.

Con la evidencia que proporciona la arquitectura, los artefactos y las fechas radiocarbónicas de los sitios del valle de Casma y alrededores, se puede construir una secuencia tentativa del desarrollo de la sociedad compleja durante el Arcaico Tardío y el Formativo Temprano. Antes de los 1800 años a.C. los sitios principales en el área de Casma fueron costeños precerámicos como Huaynuná, Tortugas y Las Haldas. Subsistieron a base de recursos marinos complementados con productos agrícolas cultivados cerca del río. Existían sistemas de comunicación entre los sitios costeños que se hacen evidentes en la elaboración de los textiles entrelazados, redes de algodón y anzuelos de concha y hueso. También, pueden haber existido líneas de comunicación entre la cos- 
ta y la sierra que se manifiestan en rasgos compartidos como el uso común del fogón ventilado (Burger y Salazar-Burger, 1980; T. Pozorski y S. Pozorski, 1996: 349-351; Shady Solís 1997: 3337).

El patrón de asentamientos cambió radicalmente alrededor de los 1700 años a.C. cuando los sitios más grandes llegaron a ser ubicados dentro del valle de Casma, en zonas óptimas para la agricultura a base de la irrigación. Este cambio representó una elección importante: Dejar la proximidad de los recursos marinos y reubicarse cerca de la fuente de los productos agrícolas abundantes que han llegado a formar el componente más importante de la subsistencia. Un resultado notable de este cambio, fue el establecimiento de los sitios de Pampa de las Llamas-Moxeke, en la rama sur del valle de Casma, y la construcción de los sitios del Complejo Sechín Alto, en la rama norte. Durante su apogeo entre 1600-1200 años a.C., estos sitios formaron una entidad política, probablemente encabezados desde Sechín Alto, que, unió el valle de Casma y la costa, entre Puerto Casma y la Bahía de Huaynuná.

Esta entidad política duró aproximadamente 500 años hasta los 1200 años a.C., período en el que se pueden distinguir cambios en los artefactos, la arquitectura y en el patrón de asentamiento. Esta última fase de desarrollo en la zona de Casma todavía no está muy bien conocida, pero parece que el foco de la entidad política cambió. La presencia de cerámica del tipo Las Haldas en los sitios del Complejo Sechín Alto sugiere que la interacción entre algunos sitios aumentó. La cerámica del tipo Las Haldas también apareció en el sitio costeño de Bahía Seca (Fig. I), encima de los niveles de basura que contienen cerámica del tipo Pampa de las Llamas-Moxeke. Este contexto provee evidencias sobre la continuación de la interacción e intercambios entre el Complejo Sechín Alto y ciertos sitios costeńos. En cambio, la ausencia de este tipo de cerámica de Pampa de las Llamas-Moxeke y los satélites costeños de Huaynuná y Tortugas, junto con la evidencia de las fechas radiocarbónicas, revelan que estos sitios probablemente quedaron desocupados.
A la vez hay indicadores arquitectónicos de una fase de construcción rápida en los sitios que seguían ocupados. Se puede notar esta expansión en: 1) La fase última de la construcción en la cima de la huaca principal del sitio de Sechín Alto durante el Formativo Temprano, que, probablemente, incluyó la construcción de plazas asociadas, visibles en la superficie; 2) la última fase de la ocupación y la construcción del sitio de TaukachiKonkán, incluye el uso continuo de la Huaca de las Columnas, la construcción de montículos adicionales que no se terminó y quizás algunas alteraciones de las plazas; y 3) la construcción del "templo" se ve claramente en la superficie del sitio costeño de Las Haldas. Hasta ahora, el uso del cuarto modular no ha sido documentado durante la fase final de la construcción rápida.

Alrededor de los 1100 años a.C. los sitios del Formativo Temprano del valle de Casma dejaron de funcionar como los centros socioeconómicos de la entidad política que dominó la zona entre los 1600 y 1100 años a.C. Con el establecimiento subsecuente de los sitios del Formativo Tardío y su patrón de asentamiento asociado ocurrieron cambios significativos. Aparecieron grandes aldeas aglutinadas, pero sin el eje central, ni la orientación predeterminada y tampoco con los grandes montículos que caracterizaron los sitios anteriores. Una de estas nuevas aldeas se estableció en la cima del montículo principal de Sechín Alto, utilizando la huaca como si fuera un cerro natural. También, durante esta época, los arrefactos y la subsistencia se transformaron con adiciones que incluyen la cerámica con pintura blanca y otros tipos de decoración, las antaras de cerámica, las puntas de pizarra, el maíz, el cuy y la llama (S. Pozorski y T. Pozorski, 1987: 118-122). Así, cambió totalmente la naturaleza de la sociedad compleja dentro del valle de Casma.

\section{AGRADECIMIENTOS}

Agradecemos al Instituto Nacional de Cultura del Perú por las credenciales y las resoluciones que permitieron la investigación de los sitios mencionados en este artículo. También agradecemos a las siguientes organizaciones, las cuales han pro- 
veído los fondos para realizar las investigaciones: National Science Foundation, Heinz Charitable Trust, J. M. Kaplan Foundation, American Philosophical Society, Netting \& O'Neill Foundation del Carnegie Museum of Natural History y Faculty Research Council de la University of Texas-Pan American.

\section{NOTAS}

1 Todas las fechas citadas en este artículo están sin calibración.

\section{BiBLIOGRAFía}

BURGER, Richard y Lucy SALAZAR-BURGER

1980 "Ritual and Religion at Huaricoto». En Archaeology, Vol. 33, №6, pp. 26-32.

CARLEVATO, Denise

1979 Analysis of ceramics from the Casma valley, Peru: Implications for the Local Chronology. Master thesis, Departament of Anthropology. Madison: University of Winconsin.

COLLIER, Donald

1962 "Archaeological Investigations in the Casma valley, Perum. En Thirty-fourth International Congress of Americanists, pp. 411-417, Vienna.

FUNG, Rosa y Carlos WILLIAMS

1977 «Exploraciones y Excavaciones en el valle de Sechín, Casman. En Revista del Museo Nacional, Vol. 43, pp. 111-155.

ISHIDA, Eiichiro et al.

1960 Andes I: University of Tokyo Scientific Expedition to the Andes in 1958. Tokyo: Bijutsushuppansha.

\section{KOSOK, Paul}

1965 Life, Land and Water in Ancient Peru. New York: Long Island University Press.

\section{MIDDENDORF, Ernest}

1973 Perú, Observaciones y Estudios del pais y sus habitantes durante una permanencia de 25 años. Vol. 2. Lima: Universidad Nacional Mayor de San Marcos.
POZORSKI, Shelia

1987 "Theocracy vs. Militarism: the Significance of the Casma Valley in Understanding Early State Formation». En The origins and Development of the Andean State editado por J. Hass, S. Pozorski y T. Pozorski, pp. 15-30. Cambridge: Cambridge University Press.

POZORSKI, Shelia y Thomas POZORSKI

1986 "Recent excavations at Pampa de las LlamasMoxeke, a complex Initial Period site in Peru". En Journal of Field Archaeology, Vol. 13, pp. 381-401.

1987 Early Settlement and Subsistence in the Casma Valley, Peru. Iowa City: University of lowa Press.

1989 "Planificación Urbana Prehistórica en Pampa de las Llamas-Moxeke, valle de Casma». En Boletin de Lima, Vol.65, pp. 19-30, Lima.

1991 "Storage, Access Control, and Bureauctatic Proliferation: Understanding the Inicial Period (1800-900 B.C.) Economy at Pampa de las Llamas.-Moxeke, Casma Valley, Peru". En Research in Economic Anthropology, Vol.13, pp. 341-371.

1992a "Resultados Preliminares del Reconocimiento y Excavación de Sitios Tempranos en el Valle de Casma: 1980-1987n. En Boletin de Lima, Vol. 80, pp. 33-45.

1992b "Early Civilization in the Casma Valley, Peru." En Antiquity, Vol. 66, pp. 845-870.

1994 "Multidimensional Planning at Pampa de las Llamas-Moxeken. En Meaningful Atchitecture editado por M. Locock, pp. 45-65, Wordwide Archaeological Series 9, Avebury.

(En prensa) "La Dinámica Cultural en el Valle de Casma durante el Período Inicialn. En Las perspectivas Regionales del Formativo Peruano editado por P. Kaulicke. Lima: Pontificia Universidad Católica del Perú. 
POZORSKI, Thomas y Shelia POZORSKI

1990 "Huaynuná, a late Cotton Preceramic Site on the North Coast of Peru». En Journal of Field Archaeology, Vol. 17, pp. 17-26.

1992 "Early Stone Bowls and Mortars from Northern Perun. En Andean Past, Vol. 3, pp. 165-186.

1994 "Sociedades Complejas Tempranas y el Universo Ceremonial en la Costa Nor-Peruana". En ElMundo Cenemonial Andino editado por L. Millones y Y. Onuki, pp. 47-70. Lima: Editorial Horizonte.

1996 "Ventilated Hearth Structures in the Casma Valley, Perun. En Latin American Antiquity, Vol. 7, pp. 341-353.

SAMANIEGO, Lorenzo y Mercedes CÁRDENAS

1995 "Catálogo de los Monolitos de Sechín". En Arqueologia de Cerro Sechín editado por L. Samanicgo et al., Tomo II, Pp. 257-412. Lima: PUCP-Fundación Volkswagenwerk.

SHADY, Ruth

1996 La Ciudad Sagrada de Caral-Supe en los Albores de la Civilización en el Perú. Lima: Universidad Nacional Mayor de San Marcos,.
TELLO, Julio C.

1956 Arqueologia del Valle de Casma, Culturas: Chavin, Santa o Huaylas Yunga y Sub-Chimú. Vol. 1. Lima: Universidad Nacional Mayor de San Marcos.

\section{THOMPSON, Donald}

1961 Architecture and Settlement Patterns in the Casma Valley, Peru. Doctoral Thesis, Departament of Anthropology.Cambridge: Harvard University.

1962 "The Problem of Dating Certain Stone-Faced Stepped Pyramids on the North Coast of Peru.nEn Southwestern Journal of Anthropology, Vol. 18, pp. 291-301.

1964 "Formative Period Architecture in the Casma Valley". En Thirty-fifth International Congress of Americanists, Vol. 1, pp. 205-212. Ciudad de México. 


\section{TABLA 1}

Fechas radiocarbónicas de pampa de las LLAMAS-MOXEKE, tAUKACHI-KONKAN, SECHÍN aLTO.

\section{PAMPA DE LAS LLAMAS-MOXEKE}

$\begin{array}{llll}\text { Número } & \text { Fecha a. p. } & \text { Fecha a. C. } & \text { Material } \\ \text { UGa-4510 } & 4655+95 & 2705+95 & \text { carbón } \\ \text { UGa-5796 } & 3745+85^{*} & 1795+85 & \text { carbón } \\ \text { UGa-4505 } & 3735+75 & 1785+75 & \text { crbón } \\ \text { UGa-5461 } & 3520+70 & 1570+70 & \text { madera } \\ \text { UGa-5462 } & 3515+70 & 1565+70 & \text { madera } \\ \text { UGa-5801 } & 3495+85^{*} & 1545 \pm 85 & \text { madera } \\ \text { UGa-4506 } & 3490+75 & 1540+75 & \text { carbón } \\ \text { UGa-5799 } & 3465+55^{*} & 1515+55 & \text { madera } \\ \text { UGa-4508 } & 3425+75 & 1475+75 & \text { carbón } \\ \text { UGa-4507 } & 3390+150 & 1440+150 & \text { carbón } \\ \text { UGa-5800 } & 3345+55^{*} & 1395+55 & \text { madera } \\ \text { UGa-4509 } & 3320+85 & 1370+85 & \text { carbón } \\ \text { UGa-5611 } & 3310+70^{*} & 1360+70 & \text { carbón } \\ \text { UGa-5610 } & 3270+50^{*} & 1320+50 & \text { madera } \\ \text { UGa-5795 } & 3245+55^{*} & 1295+55 & \text { madera } \\ \text { UGa-5609 } & 3230+60^{*} & 1280+60 & \text { carbón } \\ \text { UGá-5797 } & 3220+60^{*} & 1270+60 & \text { carbón } \\ \text { UGa-5630 } & 3190+60^{*} & 1240+60 & \text { carbón } \\ \text { UGa-5794 } & 3185+60^{*} & 1235+60 & \text { madera } \\ \text { UGa-4511 } & 3175+90 & 1225+90 & \text { carbón } \\ \text { UGa-4503 } & 3165+75 & 1215+75 & \text { carbón } \\ \text { UGa-5798 } & 3160+85^{*} & 1210+85 & \text { madera } \\ \text { UGa-5873 } & 3105+30^{*} & 1155+30 & \text { madera } \\ \text { UGa-4504 } & 3070+85 & 1120+85 & \text { carbón }\end{array}$

\section{Contexto}

Basural, lado oeste del sitio

Arquitectura doméstica, lado este del sitio

Basural inmediatamente al este de la Huaca A

Recinto inmediatamente al este de la Huaca A

Huaca A, segunda fase de construcción

Montículo del tamańo intermedio, lado oeste del sitio

Basural inmediatamente al este de la Huaca A

Arquitectura domestica, lado oeste del sitio

Basural, lado este del sitio

Basural, lado este del sitio

Montículo del tamaño intermedio, lado oeste del sitio

Basural, lado oeste del sitio

Fogón, lado oeste del sitio

Arquitectura doméstica, lado oeste del sitio

Montículo del tamaño intermedio, lado este del sitio

Basural debajo arquitectura doméstica, lado este del sitio

Montículo del tamaño intermedio, lado este del sitio

Relleno de una plaza dentro arquitectura doméstica, lado oeste.

Huaca A, segundo fase de construcción

Basural, lado oeste del sitio

Basural, lado este del sitio

Recinto inmediatamente al oeste de la Huaca A

Huaca A, segundo fase de construcción

Basural, lado este del sitio

\section{TAUKACHI-KONKAN}

$\begin{array}{llll}\text { Número } & \text { Fecha a. p. } & \text { Fecha a. C. } & \text { Material } \\ & & & \\ \text { UGa-7037 } & 3530+50^{*} & 1580+50 & \text { caña } \\ \text { UGa-7041 } & 3380+70^{*} & 1430+70 & \text { caña } \\ \text { UGa-7040 } & 3270+40^{*} & 1320+40 & \text { madera } \\ \text { UGa-7042 } & 3120+60^{*} & 1170+60 & \text { caña } \\ \text { UGa-7038 } & 3120+45^{*} & 1170+45 & \text { carbón } \\ \text { UGa-7039 } & 3005+35^{*} & 1055+35 & \text { madera }\end{array}$

\section{Contexto}

Hueco de poste, lado sur del atrio

Hueco de poste, cuarto al sur del atrio

Hueco de poste, lado sur del corte oeste

Hueco de poste, lado oeste del atrio

Cuarto con fogón ventilado, norte del corte oeste

Dentro una pilastra, cuarto al sur del atrio

\section{SECHIN ALTO sitio}

\begin{tabular}{|c|c|c|c|c|}
\hline Número & Focha a. p. & Fecha a. C. & Material & Contexto \\
\hline Beta-110593 & $3300+50^{*}$ & $1350+50$ & madera & Hueco de poste, esquina noroeste de la sección de adobes cónicos \\
\hline Beta-110592 & $3240+60^{*}$ & $1290+60$ & carbón & $\begin{array}{l}\text { Dentro } 10 \mathrm{~cm} \text { sobre el piso del cuarto profundo, } \\
\text { este de la sección de adobes cónicos }\end{array}$ \\
\hline Beta-124948 & $3240+60^{*}$ & $1290+60$ & carbón & $\begin{array}{l}\text { Basural, área doméstica en el sector sureste } \\
\text { del Complejo Sechín Alto }\end{array}$ \\
\hline Beta-124947 & $3150+60^{*}$ & $1200+60$ & carbón & $\begin{array}{l}\text { Relleno dentro } 10 \mathrm{~cm} \text { sobre el piso del cuarto cuadrado, } \\
\text { dentro del cuarto profundo }\end{array}$ \\
\hline Beta-124945 & $3140+60^{*}$ & $1190+60$ & madera & Hueco de poste, esquina noreste de la sección de adobes cónicos \\
\hline Beta-110594 & $3080+60^{*}$ & $1130+60$ & carbón & $\begin{array}{l}\text { Basural, área doméstica en el sector sureste del } \\
\text { Complejo Sechín Alto }\end{array}$ \\
\hline Beta-124946 & $3040+60^{*}$ & $1090+60$ & carbón & Relleno arriba del cuarto cuadrado, dentro el cuarto profundo \\
\hline Beta-110591 & $2210+60^{*}$ & $260+60$ & carbón & Fogón intrusivo del Horizonte Temprano sobre la escalera principal \\
\hline
\end{tabular}

(") Fechas corregidas a base de $\mathrm{C13} / \mathrm{Cl} 2$. 